\title{
Seismic risk assessment of reinforced concrete buildings
}

\author{
C. S. Dragomir ${ }^{1,2} \&$ A. S. Tronac ${ }^{1}$ \\ ${ }^{1}$ University of Agronomic Sciences and Veterinary Medicine, Romania \\ ${ }^{2}$ National Institute for Research and Development, URBAN-INCERC and \\ European Centre for Building Rehabilitation, ECBR, Romania
}

\begin{abstract}
Earthquakes originating from the Vrancea seismic source in Romania affect large areas which include neighbouring countries such as Bulgaria or the Republic of Moldova. In Romania, over $50 \%$ of the territory and population is exposed to the Vrancea earthquakes; consequently, there are many pre-code Reinforced Concrete (RC) buildings. This type of buildings should be strengthened in accordance with the European and National Codes in force. Different scenarios of dynamic amplification on physical models tested on shaking tables in the laboratory and actual case studies were examined as to the provisions in force. The objective of this contribution is to propose a control method based on both seismic monitoring and the structural analysis of a RC building. The building considered was designed as a five stories masonry structure with reinforced concrete cores that was erected during the 1950s. The paper aims to assess the $\mathrm{RC}$ building by comparatively presenting the strengthening techniques of irregular RC buildings with reference to their structural performance. It suggests alternative solutions based on modern technologies and provides a practical and applicable interpretation of dynamic amplification at the upper part of buildings. In conclusion, it may be said that seismic instrumentation is an essential tool both for assessing building behaviour and monitoring RC building rehabilitation. The major outcomes of the collaborative research in the field of seismic risk assessment are outlined and a modern assessment concept is presented.
\end{abstract}

Keywords: building assessment, structural analysis, temporary seismic instrumentation, building strengthening. 


\section{Aspects on Romania seismicity and necessity for strengthening the existing buildings}

Seismic hazard in Romania is dominated by the Vrancea intermediate depth source, leading to earthquakes in the south-eastern area; each strong event highly affects about $50 \%$ of the territory with high intensities (Balan et al. [1]). In Romania, earthquake design began in 1942, following the Vrancea earthquake on the 10th of November 1940.

It is well known that the tall buildings erected before 1940 and some structural types built between 1950 and 1977 proved to be highly vulnerable, and the Vrancea earthquake on the 4th of March 1977 was a national disaster.

The major Romanian earthquakes pointed out the necessity of strengthening the pre-code high-rise buildings, as a critical point in the advancement of risk reduction programmes, primarily in the central area of Bucharest.

In this context, investigation focused on building B of the University of Agronomic Sciences and Veterinary Medicine of Bucharest. The building consists of five stories (basement, ground floor, two floors and an attic) and was proposed for strengthening by the Technical Report developed in 2012.

Measurements were carried out before the strengthening works in order to determine their oscillation period. They resulted in a partial analysis of the dynamic parameters which led to the structural analysis of the building and finally to a modern strengthening solution.

\section{Geometrical characteristics of irregular plane and seismic joint}

Irregularity issues were dealt with in compliance with Eurocode 8 by analysing the relative relation between the rotation centre $\mathrm{CR}$ and the gravity centre CG. Thus, the position of the two centres was analysed for the selected structure, subsequently emphasising the eccentricities between the two centres and the conditions for the geometric irregularity requested by the two above-mentioned standards.

The condition of the plan geometric regularity in compliance with the Romanian seismic design code P100-1:2006 is:

$$
S_{\text {anvelope }}-S_{\text {floor }}<15 \% S_{\text {floor }}
$$

In the case of an L shaped-plan, as presented in Figure 1, equation (1) becomes:

$$
S_{\text {anvelope }}-S_{\text {floor }}=108,00 m^{2}>15 \% S_{\text {floor }}
$$

It was noted that the L shaped-plan with the dimensions shown in Figure 1 did not satisfy any of the conditions in accordance with the regular rules. The conclusion was that the chosen construction type had no regularity in the plan. 
From the viewpoint of the simplified calculation scheme, the inertia force $F_{i}$ was applied to the gravity centre CG of the cross section. Hence, the expression of the global torsion moment was:

$$
M_{x}=r F_{i}
$$

where $M_{x}=$ torsion global moment; $r=$ seismic force arm; $F_{i}=$ seismic force, in accordance with the Romanian seismic design code.

Further on, the solution for mitigation of the global torsion moment consisted in sectioning the L-shaped structure by a seismic joint.

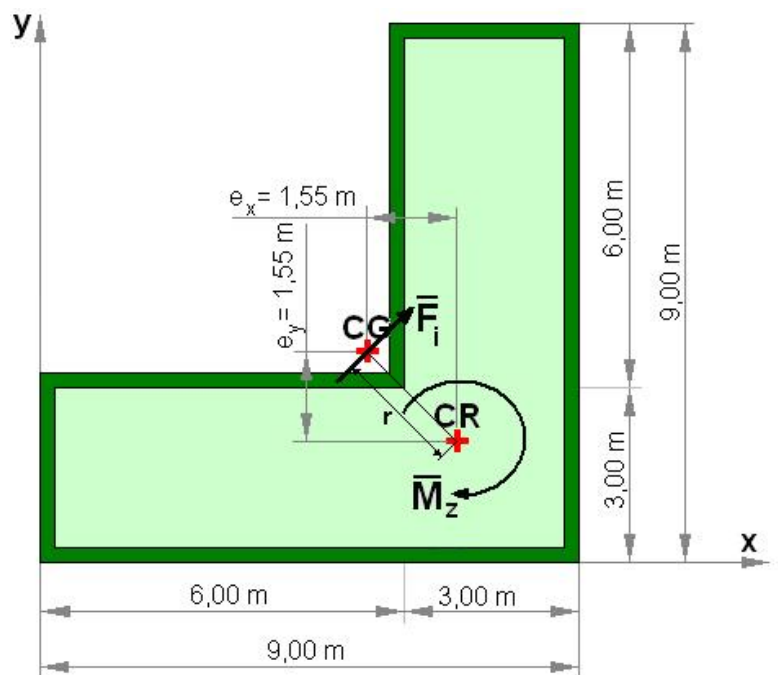

Figure 1: Representation of inertial force.

In compliance with the seismic design code concerning the structures designed for a similar safety level with close dynamic and size characteristics, the joint dimension was determined by the relation:

$$
\Delta=d_{1}+d_{2}+20 m m
$$

In order to investigate seismic pounding between two closely-spaced, adjacent structures, a simplified model was developed.

All nonlinearities were restricted to the nonlinear link elements only. The dynamic equilibrium equations obtained from the equilibrium of all forces at each degree of freedom could be written as:

$$
[M]\{\ddot{U}\}+[C]\{\dot{U}\}+[K]\{U\}+\left\{F_{c}\right\}=-[M]\{I\} \ddot{u}_{g}
$$


where $[M],[K]$ and $[C]$ were the mass, damping and stiffness matrices of the structure; $\{U\}$ the displacement vector of structure; $\ddot{u}_{g}$ is horizontal ground motion; $\{I\}$ is the earthquake influence coefficient matrix and $\left\{F_{c}\right\}$ is the contact force vector due to pounding,

$$
F_{c}=\left\{\begin{array}{c}
k\left(u_{1}-u_{2}-g_{p}\right)+c\left(\dot{u}_{1}-\dot{u}_{2}\right), u_{1}-u_{2}-g_{p}>0 \\
0, u_{1}-u_{2}-g_{p} \leq 0
\end{array}\right.
$$

The relation $u_{1}-u_{2}-g_{p}$ was the relative displacement and $g_{p}$ is gap width.

When there was no pounding between the two buildings, $\mathrm{B}_{1}$ and $\mathrm{B}_{2}$, the impact springs did not occur and the values assigned to $k$ were zero in $F_{c}$, i.e. $k=0$. Contact occurred between the lumped masses at the floors when the condition was satisfied.

\section{Temporary seismic instrumentation}

According to the modern approach of preparedness, post-seismic interventions should be clearly foreseen and properly planned in order to avoid additional damages and fatalities, and to save what remained worth for further use. The strengthening solutions should be designed and organised according to the ISO13822:2001 provisions.

All buildings behave beyond the elastic range during the earthquake, which implies the change in all dynamic characteristics. It is obvious that the structure is left with modified physical and mechanical characteristics after the ground motion ends. Thus, from the earthquake-caused degradation, building stiffness decreases while the proper periods and the percentage of critical damping increase.

An important element involved in calculating the buildings subject to seismic forces is their own vibration period whose experimentally determined value can provide an indication of the stiffness and resistance capacity level of the structure to horizontal seismic forces.

Consequently, it is important to measure the vibration periods of the buildings in different situations, as follows: after their release to service, before the earthquake, after the effect of the earthquake that has caused damage and weakened the structure, or after strengthening and reinforcement. This allows the determination of the rigidities and therefore a very useful assessment of the degree of damage and resistance capacity of buildings (Dragomir and Calin [2]).

In order to determine the proper rotation period in the horizontal plane (known as the proper period of overall torsion), it is necessary to perform a series of recordings of the synchronous oscillations occurring in pairs of points located at large distances from the stiffness centre. The latter is assessed by the experimenter, on the same floor of the building (preferably the top floor). If the floor has a rotation movement in plane, the extreme points of the selected pairs will move in phase opposition. 
Owing to the nature of the chosen movement points, the processing of the sum and difference signals for the mentioned pairs, by using similar methods as the above ones, allows the determination of their rotation periods in the horizontal plane (torsion). In most cases, when the fundamental mode of oscillation predominates, it is easy to determine their basic forms (for the oscillations that occur in the two main planes of the building).

Experimental determination of the critical damping fractions can be performed based on the autocorrelation properties of the response function.

The rotation influence of foundations on the field may have important effects for the buildings located on a ground with high deformation. The share rotation on the ground from the total response of the building can be determined based on experimental data. The conclusions that can be drawn refer only to the linear behaviour of both ground and building.

The method for determining the foundation rotation is based on seismometers recording the vertical oscillations of the building at the foundation level. Recordings are performed in two main points situated in the main vertical plane and analyse the oscillations of the building that are located at its extremities, wherever possible.

Floor deformation under dynamic conditions can be emphasized by seismometers located in a large number of points (on the floor level, on a straight line) as it is a method that allows recording of the floor deformations at different times. Deformation occurs mainly in constructions with special shapes in plane and with large openings of the floors; therefore, the way horizontal forces are transmitted to the vertical resistance structure is very important.

\section{Structural analysis of existent buildings}

One of the methods developed for assessing the vulnerability of the existing buildings is the pushover analysis which is performed by subjecting a structure to a monotonically increasing pattern of lateral loads - in fact, the application of vertical loads, followed by the application of lateral forces and the gradual imposition of a displacement to the peak of the structure. Using a pushover analysis, a characteristic non-linear force-displacement relationship can be determined in order to approximate how structure behaves after exceeding the elastic limits (Naga et al. [3]). This curve is the proper characteristic of the structure and depends on the chosen control point which is generally located on the top floor of the building or on the corresponding gravity centre of the distribution of horizontal forces.

Once a capacity curve and demand displacement is defined, a performance check can be done since the intersection of these two curves approximates the response of the structure. Performance verifies that structural and non-structural components are not damaged beyond the acceptable limits of performance objectives for the forces and displacement implied by the displacement demand.

According to FEMA-356 [4], these are the following stages of plastic hinges which correspond to different performance levels in a building. 
In the Romanian seismic design code, the mechanism with plastic potential is satisfactory when all hinges generally occur on the beams, even though they are absent on a certain one. Indeed, even if one or a few hinges occur on the extreme part of the columns on a certain level, a 'weak type' mechanism can be formed so long as most elements are functionally elastic. In this case, displacements are controlled and plastic rotations of columns articulations are quite moderate.

\section{The concept of building performance assessment}

The concept of building performance assessment is based on both structural analysis and temporary seismic instrumentation. The concept proposes the validation of calculations by a programme dedicated to structural analysis using instrumental data processing techniques.

The structural model presented in Figure 2 was based on a modular square grid $3.90 \times 3.90 \mathrm{~m}$ and a floor height of $2.75 \mathrm{~m}$, consisting of two openings and two bays, which comprised a single structural wall.

To emphasize the behaviour of the damaged building in case of a future major earthquake, the following steps were followed:

- Determination of the building vibration periods by microseismic measurements and data processing;

- Modelling a spatial structure identical to the considered one;

- Time-history analysis to determine the structure response spectrum by using the accelerograms recorded in the major Romanian earthquakes in 1977, 1986 and 1990.

Following the above steps, microseismic measurements were made on the experimental model by using two sensor placement schemes: one on the horizontal and the other on the vertical direction. Measurements were made both by applying shocks in the centre of the 2 nd floor and the microseismic movement on the site.
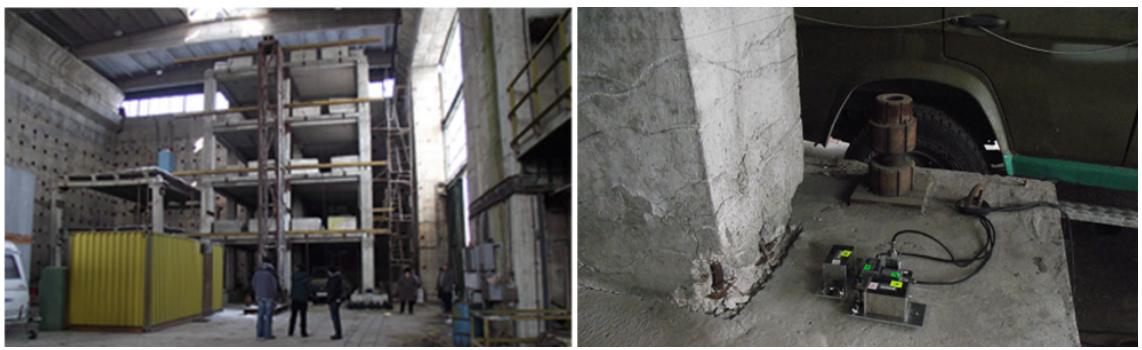

Figure 2: Experimental model and sensor disposition on foundation model.

According to the Fourier spectra analysis, the dynamic characteristics of the model were evaluated as $0.60 \mathrm{~s}$ on direction $\mathrm{X}$ and $0.32 \mathrm{~s}$ on direction $\mathrm{Y}$.

Based on the results obtained on site by temporary seismic instrumentation, a structural model with identical dynamic characteristics can be modelled; thus, 
the behaviour of the existing structure can be studied under strong earthquakes in Romania.

According to the results of modal analysis, the values corresponding to the building vibration periods were $0.64 \mathrm{~s}$ and $0.34 \mathrm{~s}$ on the two horizontal directions, and $0.49 \mathrm{~s}$ for the torsion mode, respectively.

It was noticed that the reinforced concrete diaphragm was arranged along the direction $\mathrm{Y}$ of the structural model.

Further, the accelerograms of the major earthquake produced in Romania in 1977, 1986 and 1990 were used for the time-history analysis.

The linear modal time-history analysis provided the results for the structural system studied as movement variations in a node located at the top level and at the basis of the structure. The maximum values of displacements, corresponding to nodes 47 (at the top of the building) and 23 (at the basis of the building) under major Romanian earthquakes, are presented in Figure 3.

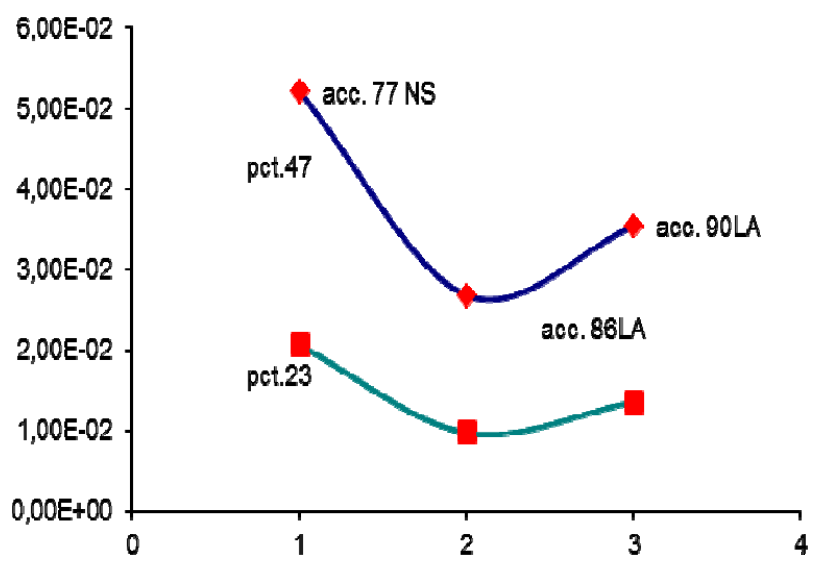

Figure 3: Maximum values of building displacements.

\section{Case study: performance assessment of the faculty building}

The case study presents the applicability of building performance assessment on the Bucharest educational building presented in Figure 4.

Taking into account the shape and size of the building plan, the building was divided into two distinct wings through an expansion joint of $2.00 \mathrm{~cm}$. The section of the main entrance and lecture hall area was named $\mathrm{B}_{1}$, and the other one was called $\mathrm{B}_{2}$.

Figure 5 shows that the $2.00 \mathrm{~cm}$ expansion joint played no role as a seismic joint since the two wings pounded with each other, probably owing to their different rigidity since the two wings have large heights (Dragomir et al. [5]). 


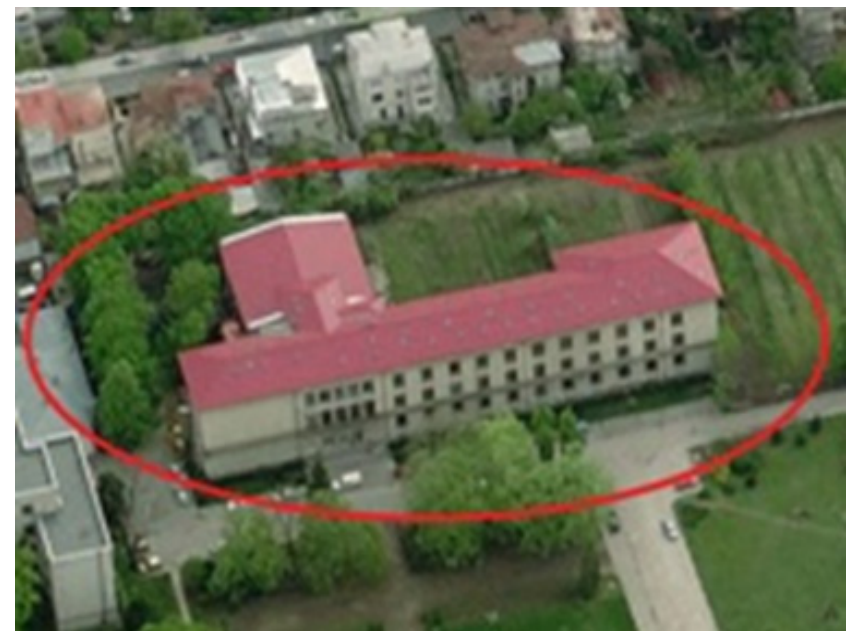

Figure 4: General view of faculty building.

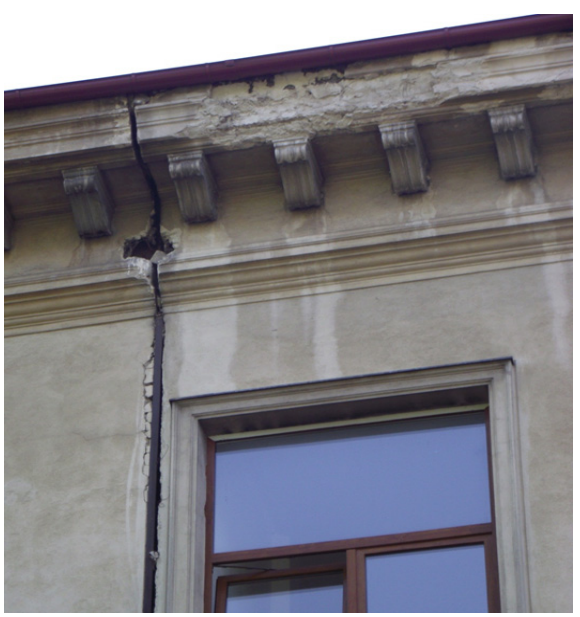

Figure 5: General view of faculty building.

The two wings of the building are irregular in shape and their eccentricities between CG and CR highly exceed the standard values (Figure 6), (Dragomir et al. [6]).

In order to solve this problem, one of the strengthening solutions was to divide the building into sections by a seismic joint that separated the large lecture hall. This resulted in two buildings with approximately rectangular shapes. The design focused on each wing separately, and the spatial computing models validated by micro-seismic measurements aimed to achieve the safety level required by the codes. 


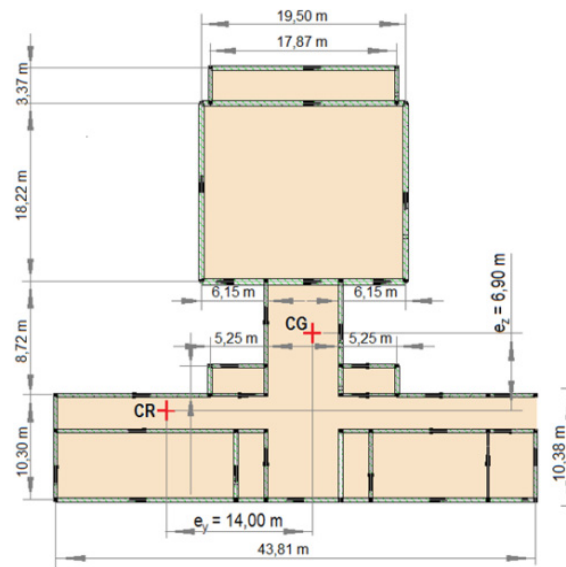

(a) $B_{1}$ wing shape

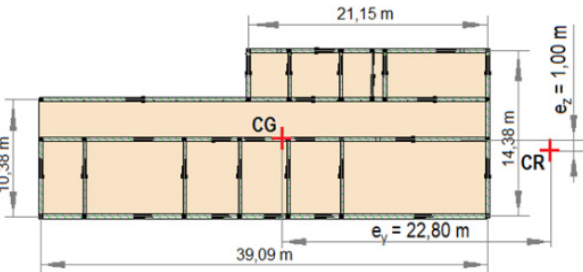

(b) $\mathrm{B}_{2}$ wing shape

Figure 6: Eccentricities according to the two orthogonal directions.

The recording of the dynamic parameters was performed in September 2012 by using a micro-seismic data acquisition equipment endowed with 12 channels and four tri-axial sensors placed in different directions. The resulting values of oscillation periods were $0.40 \mathrm{~s}$ on the transversal direction and $0.28 \mathrm{~s}$ on the longitudinal direction.

The two wings separated by the expansion joint have different strength structures and there are no reinforced concrete pillars at the intersection of the load-bearing brick walls for strengthening these areas.

The building has an irregular shape in plan and elevation, and the expansion joint is damaged, which means that the two buildings clashed in the earthquakes that occurred over the past 60 years. Therefore, the expansion joint has failed to fulfil the function of seismic joint.

According to the Technical Report developed in 2012, the following characteristics were similar to the building materials used: C100 bricks, M10 mortar cement, R28 concrete - $120 \mathrm{daN} / \mathrm{cm}^{2}$, current class C12/15 and OB37 concrete steel.

These characteristics were used in performing the structural analysis of the existent building.

Investigation focused on the seismic behaviour of two closely spaced 3-D concrete frame bodies of the faculty building, designed at the same height but with different characteristics. The nonlinear elastic gap elements and the nonlinear modal history analysis and the 1977 Vrancea accelerogram were used to create the pounding model, (Dobre et al. [7]). The dynamic characteristics of structural system evaluated on two horizontal directions were: $0.39 \mathrm{~s}$ on the transversal direction and $0.36 \mathrm{~s}$ on the longitudinal direction.

To emphasize the pounding situations when the condition was satisfied, some modal displacements for two points at the top of each body were represented in Figure 7, according to the vibration modes. 


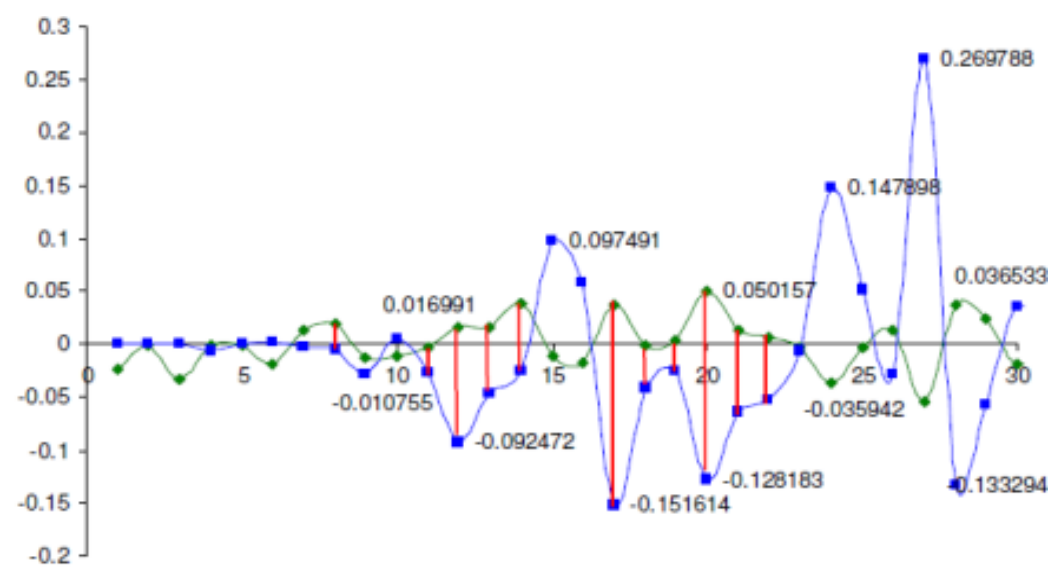

Figure 7: Modal displacements of the two bodies of faculty building.

The safety levels deriving from the new requirements were lower than the ones previously recorded by the old standards due to the different definitions of the seismic hazard: MRI (Mean Recurrence Interval) $=50$ years for the previously seismic design code, and MRI $=100$ years for the present seismic code, which led to higher values in the latter requirement and hence lower values of the safety level.

It is imperative to strengthen the building of the faculty. In addition to the strengthening solution presented here, building systems based on composite materials can be adopted in various forms which can be applied on one or both sides of the wall. The solution is present among the strengthening measures included in P100-3:2008. In this case, the shear force capacity of the masonry wall plated with composite materials is given by the contribution of the composite material and the masonry itself.

\section{Modern solution for building strengthening}

One of the modern solutions used today for strengthening the RC frame buildings with masonry infill walls consists in strengthening the masonry panels with carbon fibre fabric. The aim of the study was to test for bending four models of masonry made of ceramic blocks, with the same plan dimensions, $1.50 \times 1.00 \mathrm{~m}$, but with different thickness: 2 models with $30 \mathrm{~cm}$ thickness (M30) and 2 models with $38 \mathrm{~cm}$ thickness (M38).

The two models were strengthened on the side in tension with carbon fibre fabric. Epoxy resin was used for applying the fabric.

Figure 9 presents a comparison between the force-arrow diagrams for the two versions of the M30 and M38 models, i.e. plain and strengthened.

The failure of the two modules led to the conclusion that masonry had exceeded its compressive resistance. 

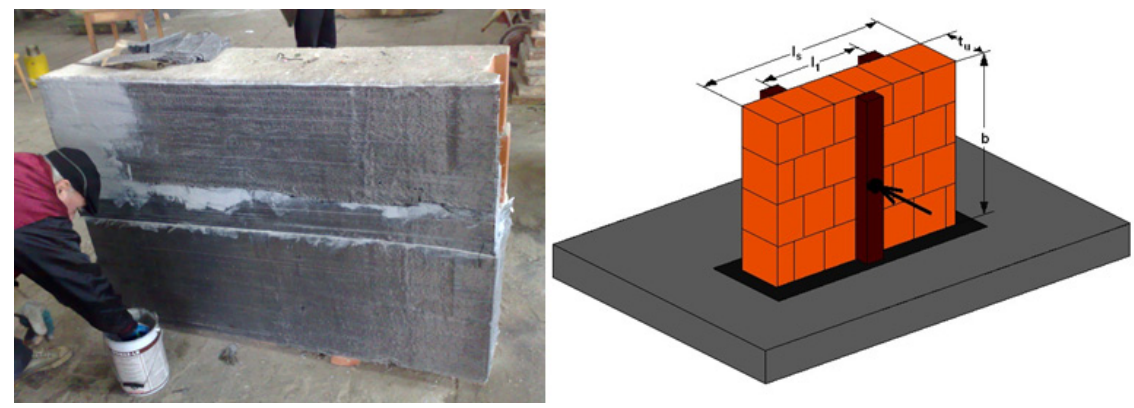

Figure 8: Strengthening solution with bending test setup.

Under the conditions of the tests, the contribution of the block size to rigidity was greater than the contribution provided by applying a double number of carbon fibre layers; a single layer of fabric was sufficient as the advantage of an increased number of layers could not be exploited.
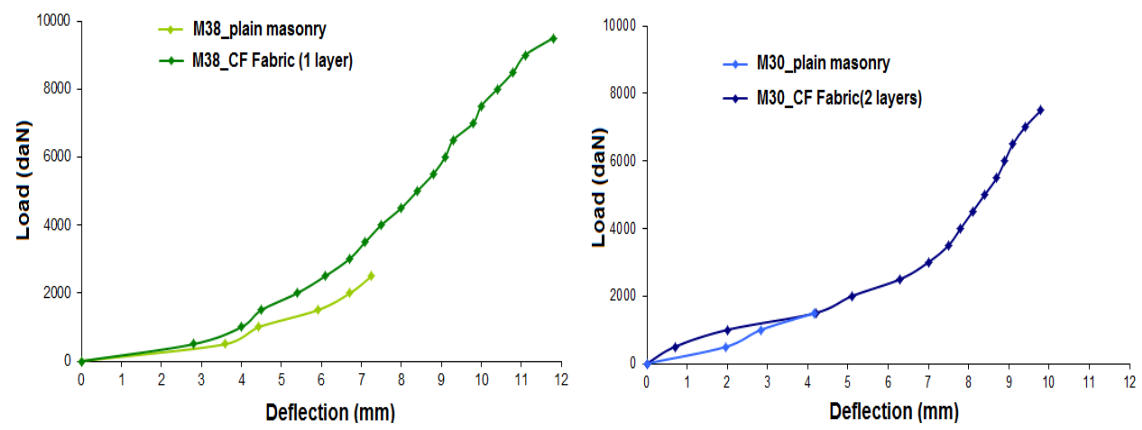

Figure 9: Force-arrow diagrams for M30 and M38 models.

\section{Conclusion}

The effects of dynamic amplification and proportions of damages were evaluated. Geodynamic methods were used for this purpose, based on the microseismic station with four three-axial sensors and adequate software for data processing. Assessment was useful for both the seismic risk analysis of the inspected buildings and the design of the strengthening interventions.

The concept of building performance assessment proposes the validation of calculations by a programme dedicated to structural analysis using instrumental data processing techniques.

The pounding effects between two adjacent buildings on the behaviour of structures, often characterised by different material properties and under earthquake input, can cause both architectural and structural damages. The effects have often involved the partial or total collapse of buildings therefore 
the study of the pounding between buildings is important, considering the seismicity of the Vrancea area.

The tests made on masonry panels confirm the efficiency of composite materials.

\section{References}

[1] Balan, St., Cristescu, V. \& Cornea, I., The Romania Earthquake of 4 March 1977. Academiei Publishing, Bucharest, Romania, 1982.

[2] Dragomir, C.S. \& Calin, M.C., Dynamic response parameters and damage assessment of educational building located in earthquake prone area, Proc, of 15th World Conference Earthquake Engineering in Lisbon, Portugal, paper no. 1940, 2012.

[3] Naga, S.S., Phanisha, K., Mohana, R.N., Sarkar, S. Nageswari, M. \& Poluraju, P., Determination of Performance Level of G+5 Building Situated In Zone III Using Pushover Analysis by Sap2000, International Journal of Engineering Research and Applications (IJERA), 2(2), pp. 832-837, 2012.

[4] Federal Emergency Management Agency, FEMA-356, Prestandard and commentary for the seismic rehabilitation of buildings, Washington DC, pp 2.1-2.30, 2000.

[5] Dragomir, C.S., Purdoiu S., Tronac, A.S., Campeanu, S.M. \& Bucur, R.D., Assessment of structural damages using non-destructive and seismic instrumentation methods. Case study of educational building in Bucharest. Proc. Of 2nd International Conference of U.A.S.V.M., Agriculture for Life, Bucharest, Romania, Series E, Vol. 2, pp. 91-96, 2013.

[6] Dragomir, C.S., Ionita, A., Tronac, A.S., Georgescu, E.S. \& Iorga, F., Protection of built environment by seismic instrumentation, Proc, of International Multidisciplinary Scientific Geoconference (SGEM), Albena, Bulgaria, pp. 855-862, 2013.

[7] Dobre, D., Dragomir, C.S., Borcia, I.S. \& Georgescu, E.S., Modeling Seismic Response Of Adjacent Buildings Under Vrancea Earthquake Input, Proc. of International Conference of Earthquake Engineering, Skopje, Republic of Macedonia, paper no. 165, 2013. 